This item was submitted to Loughborough's Research Repository by the author.

Items in Figshare are protected by copyright, with all rights reserved, unless otherwise indicated.

\title{
The role of formal controls in facilitating information system diffusion
}

\section{PLEASE CITE THE PUBLISHED VERSION}

http://dx.doi.org/10.1016/j.im.2015.04.005

\section{PUBLISHER}

(c) Elsevier

\section{VERSION}

AM (Accepted Manuscript)

\section{PUBLISHER STATEMENT}

This work is made available according to the conditions of the Creative Commons Attribution-NonCommercialNoDerivatives 4.0 International (CC BY-NC-ND 4.0) licence. Full details of this licence are available at: https://creativecommons.org/licenses/by-nc-nd/4.0/

\section{LICENCE}

CC BY-NC-ND 4.0

\section{REPOSITORY RECORD}

Abubakre, Mumin Adetunji, M.N. Ravishankar, and Crispin Coombs. 2019. "The Role of Formal Controls in Facilitating Information System Diffusion”. figshare. https://hdl.handle.net/2134/17714. 


\title{
THE ROLE OF FORMAL CONTROLS IN FACILITATING IS DIFFUSION
}

\begin{abstract}
Information systems (IS) studies highlight that IS usage, a pre-requisite for IS diffusion, may be difficult to attain when usage is voluntary because users can resist using the system. User resistance may be overcome through the application of organizational controls. Control theory explains how users' actions and practices are shaped in line with organizational guidelines and procedures. This paper reports on a qualitative case study and shows how formal control mechanisms (behavior and outcome controls) can have a positive and conclusive impact on IS diffusion. The paper makes three contributions to knowledge. First, it explains how the application of outcome control mechanisms can lead to IS diffusion despite user resistance. Second, it suggests that IS diffusion paths are iterative, rather than smooth and linear. Finally, the paper demonstrates that in some contexts, despite a lack of reward expectancy, sanction expectancy can be an effective force during the IS diffusion process.
\end{abstract}

Keywords: IS implementation, user resistance, IS diffusion, organizational control 


\section{Introduction}

Many organizations fail to make a return on the huge investments they make in information systems (IS) implementations [1, 17]. This is usually because employees do not use the IS in a sufficiently enhanced manner to increase effectiveness and efficiency and improve productivity of the adopting unit [45]. Thus, employees prevent the diffusion of the system into the organizational setting [1,2]. It is difficult to attain enhanced IS usage in voluntary settings due to the fact that users have the option to resist using the system [17, 52], and thereby only engage superficially with it. User resistance has been identified in the literature as a key reason why companies struggle to attain successful IS diffusion [50]. This has led IS scholars such as Williams et al. [53] to argue that there is still much to learn about IS diffusion. It also begs the question of how user resistance can be overcome in order to attain successful IS diffusion. The answer to this may lie in an examination of organizational controls, which are applied to overcome strong user resistance that sabotages IS implementation attempts, and thereby inhibits IS diffusion [17, 54].

IS studies have drawn on control theory to demonstrate the importance of applying formal control mechanisms in the management of IS projects $[8,20,21]$ and in the development of such projects in custom and outsourced contexts [7]. Nonetheless, no research to date has explicitly studied how formal controls can facilitate the successful diffusion of a complex IS. In this paper, we use behavior and outcome controls as lenses through which to conceptualize formal controls $[7,23]$. Through these lenses, we develop insights into how organizations can overcome users' rejections of IS and achieve conclusive and positive IS diffusion via the application of formal controls, which in turn increase the likelihood of getting a good return from IS investments. We make three main contributions to research. First, we explain how the application of formal controls can lead to successful IS diffusion despite user resistance. Second, we suggest that IS diffusion paths are iterative and non-linear, which contradicts existing studies highlighting diffusion as a linear and sequential process [e.g. 10, 39]. Third, we demonstrate how in some contexts despite the lack of reward expectancy, sanction expectancy can be effective in the application of controls during the IS diffusion process. This extends existing research on controls, which suggests that in order to ensure the effectiveness of applied controls, reward-sanction mechanisms should be utilized in tandem $[22,25]$.

We adopted the qualitative case study method to understand how senior management's application of formal control mechanisms in a Nigerian multinational bank influenced 
employees engagement with an IS, and thus impacted IS diffusion. Specifically, the study sought to answer the following research questions: (1) How and when are formal controls applied during the organizational diffusion of an IS? (2) What are the consequences of applying formal controls to the process of IS diffusion? In order to answer these questions we drew on Cooper and Zmud's [10] six-stage IS implementation model, a model that describes the different stages that come into play during attempts to diffuse a complex IS into an organization. The following section discusses the theoretical foundation of the paper. Subsequently, we describe the research methods and outline our findings. Finally, the discussion and conclusions are presented.

\section{Theoretical foundation}

In this section we review and synthesize: (1) IS diffusion theories and related streams of technology acceptance and IS success research; and (2) formal control modes and mechanisms and their application in IS research.

\subsection{IS diffusion}

Existing studies on IS diffusion have suggested that the diffusion process consists of a series of stages and during each stage a sequence of events and activities unfold [38]. Several theoretical models have been proposed in the IS literature to explain the diffusion patterns of IS implementations [see 10, 12, 38, 47]. One of the most frequently cited models is the Cooper and Zmud [10] IS implementation model. Cooper and Zmud's [10] model suggests that in the process of achieving diffusion, IS implementations typically progress through six stages: initiation, adoption, adaptation, acceptance, routinization, and infusion (see Figure 1). Initiation refers to organizations' launching of technological innovations to solve problems or respond to opportunities. Adoption highlights the rational and political negotiations required to ensure that top IS and business executives agree to invest in an IT system and the required resources to accommodate the new system. Adaptation refers to the development, installation and maintenance of the adopted IS. Acceptance is a critical stage because this is the phase when employees are expected to employ the IT artefact in their work. In many ways, this stage will determine whether the system is likely to be accepted or rejected. Routinization

refers to the stage when the use of the IS becomes a normal and routine activity in the organization. Finally, infusion is concerned with the increased organizational effectiveness obtained from utilizing the implemented IT system to its full potential in a more comprehensive and integrated manner. 


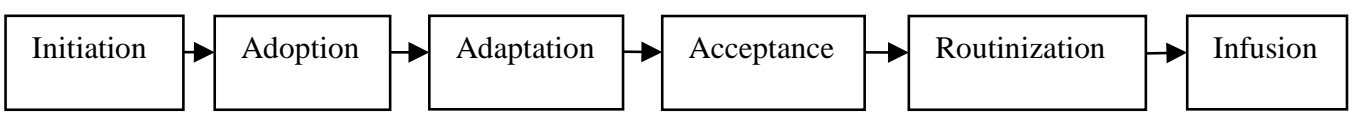

Figure 1 Cooper and Zmud's [10] IS implementation model

A feature of Cooper and Zmud's [10] six-stage model is that it considers the continued organizational use of an IS after go live through the acceptance, routinization and infusion stages [45]. It is in these last three stages that key IS exploitation activities are likely to occur, enabling an organization to use the IS to its full potential and attain higher performance [18]. However, IS diffusion may be difficult to achieve in these post-adoption stages because of the need to overcome barriers to the assimilation of new work processes and designs by users [37]. Further, previously silent users that are now required to engage with the system in their everyday work may voice their dissatisfaction with the IS and there may be calls for modifications to the system [49]. Although strategies have been proposed to overcome these barriers, such as increased training for users [37] and increased user participation [49] these actions are more commonly performed as pre-implementation activities, along with IS configurations and customizations. Unfortunately, the post adoption stages are often devoid of the organizational resources necessary to facilitate IS diffusion [37, 49]. For example, project teams are likely to have disbanded, external consultant contracts ended and senior managers' focus and attention is likely to have moved to the next business challenge. Thus, achieving successful IS diffusion in organizations at the first attempt remains a significant challenge.

A further obstacle to IS diffusion stems from the possible misalignment of technology with organizational culture, or the weak alignment of the extant organizational culture with the requirements of technology [5]. Much of the existing IS literature has assumed that culture is homogenous within and across all subgroups and has not specifically considered the effects of competing sub-cultures, and resulting conflicts and opposition to IT outcomes that may occur between organizational subgroups. When subgroup interests conflict during the implementation of a new IT system, user resistance may occur [1]. For example, Ravishankar et al. [36] demonstrate that different subcultures can influence the alignment of an IS with organizational strategy. In their case study of a knowledge management system implementation, the 'enhancing' subculture highlighted a subgroup that maintained a strong empathy with the strategic initiatives advocated by the senior management. By contrast, the 'countercultural' subgroup obstructed the senior management initiative to align the 
implemented IS with organizational strategy. Cavusoglu et al. [6] provide related findings. They studied three groups of actors: 'influentials', 'opponents' and 'imitators'. The opponent group behavior (resisting IS usage) created significant anti-diffusion forces. The opponent group's resistance to the IS stifled the positive behavior exhibited by the influential group toward the IS. This prompted the imitators to copy the behavior of the opponent group, which further hindered the diffusion process. To overcome such problems, an organization might consider applying formal control mechanisms to align different subgroup interests.

There are a number of alternative streams of literature that seek to explain successful IS diffusion. For example, Venkatesh et al. [47] developed the Unified Theory of Acceptance and Use of Technology (UTAUT) to explain the adoption and acceptance of IS by individuals. The UTAUT presents four critical determinants of user acceptance and usage behavior: performance expectancy, effort expectancy, social influence and facilitating conditions [48]. The effect of these determinants on behavioral intention was moderated to varying degrees by four factors: age, gender, voluntariness, and experience. For example, performance expectancy, the extent an individual perceives using an IS will increase their productivity, was found to have a stronger influence on behavioral intention for men and younger workers [47]. Thus, it would appear that individual intention to use an IS can vary between different user groups within an organization, such as women, older workers or those with limited experience. While these predictive insights are valuable at an individual use level, the UTAUT model does not provide guidance on how to plan interventions at an organizational level. In this respect the usefulness of UTAUT is limited for examining mechanisms to promote the continued use and success of an implemented IS [3].

Researchers have developed several models for examining IS success, the most frequently cited being the IS-success and IS-impact models [13, 15]. Although these models have provided valuable guidance for understanding IS project success they have been most frequently applied to explain success in voluntary IS use situations. In many organizations the use of IS at the enterprise level systems is often mandatory rather than voluntary. Under these circumstances scholars have questioned the appropriateness of the 'use' construct in the IS-success model [45]. For example, Seddon and Kiew [42] argued that for mandatory systems, 'usefulness' rather than 'use' may be a more appropriate construct to measure and Brown et al. [4] report differences in technology acceptance between mandatory and voluntary systems. DeLone and McLean [13] responded to these studies arguing that even for mandatory systems there can be variability of use and that the 'use' construct should be 
retained. More recently, Petter and McLean [33] investigated whether voluntariness of the IS influenced the relationship between use and user satisfaction. They found that voluntariness did not moderate their results but cautioned against disregarding this condition to explain IS success. This has led to continuing calls for further studies to investigate whether mandatory or voluntary conditions are moderators or direct determinants of IS success [34]. In sum, the IS success literature highlights the potential importance of whether users are allowed discretion in the use of an IS, but clear guidance regarding the influence and application of mandatory controls to achieve the successful IS diffusion is lacking.

A further related stream of literature highlights the term 'technology-use mediation' (TUM), as suggested by Orlikowski et al. [30]. This stream of research explains that managers adopt different intervention methods to influence members using IS [see 11, 30, 43]. This stream overlaps with our application of control, but also differs significantly because actions put in place by senior managers in the TUM context highlight an inclusive and encouraging, but not a direct approach [30]. Our study proposes a direct and forceful approach to control, which is needed to overcome strong IS resistance that sabotages IS diffusion attempts. Thus, we argue that the TUM approach may not be effective in an environment where user groups vehemently reject the introduction of a new IS.

\subsection{Formal control modes and mechanisms}

Formal controls allow controllers (e.g. managers) to use company policies, guidelines, rules or procedures in a formal, documented manner to influence controlee (e.g. employee) actions to achieve desired behaviors or outcomes [14, 22]. These formal control mechanisms contrast with informal control mechanisms, which rely on social or norm-emphasizing strategies to ensure that set objectives are met by the controlees [7, 21]. Newell et al. [28] note that a portfolio of informal controls may be difficult to enact because of differences in group and stakeholder behavior while attempting to undertake a complex IS project. Further, Jaworski [19] and Kirsch [21] suggest that formal control modes could be more appropriate for larger projects, while informal control modes may be more suited to smaller projects. These studies suggest that informal controls may be less effective for complex IS projects in large organizations involving different groups and stakeholders. Thus, in this study we only focused on the application of formal controls in an IS project.

Two types of formal controls are commonly identified in the literature - behavior and outcome controls [31]. In the application of behavior controls, the controller explicitly 
specifies rules and procedures to the controlee that are to be followed in order to achieve desired tasks. For example, Kirsch [20] documented how an IS development manager applied behavior controls to ensure that a project manager included a specific functionality during the development of a complex IS. The IS development manager used behavior control mechanisms such as regular meetings with the project manager to monitor the project manager's progress and to redirect work as necessary.

In the application of outcome controls, the controller defines specific task outputs, sets appropriate targets for these outputs, but gives controlees the discretion to choose how they achieve the output targets. The controller evaluates the controlee's performance by examining the degree to which targets are met. Thus, unlike behavior controls, the controller does not monitor compliance with specific task procedures as a method to ensure targets are met. For example, Kirsch et al. [23] reported how clients used outcome controls such as scheduling and specification of deliverables to stipulate required system developments to project leaders, while permitting the project leaders to choose how they fulfilled the delivery of those requirements. Choudhury and Sabherwal [7] also show how client testing of software deployed by a vendor served as an outcome control mechanism that helped the client (the controller) measure the vendor's (the controlee) performance against the specified outcomes of an IS project.

Despite differences in the application of behavior and outcome controls, both types of control share a common assumption that controllers and controlees have contrasting goals, which can be aligned by providing appropriate incentives in the form of a reward/sanction system [25]. For example, in studying the dynamics of control mechanisms during different IS project phases, Kirsch [22] found that reward/sanction mechanisms were utilized by both IS and business stakeholders to ensure the successful installation of an open system and associated business process change. Thus, senior management may choose to establish policies to mandate and specify how employees are expected to engage with, and use an IS [52] thereby ensuring the attainment of IS diffusion and enabling the organization to realize benefits from its IS investments.

Previous models and studies have not considered the influence of formal controls on the low levels of IS usage caused by user resistance to an IS. Our research builds on the control literature and uses Cooper and Zmud's [10] six-stage IS implementation model to understand how formal controls may facilitate IS diffusion. We chose Cooper and Zmud's [10] IS 
implementation model because it considers both pre and post adoption stages of IS diffusion, the latter being vital to provide a complete understanding of how the diffusion process unfolds [18, 45]. Further, Cooper and Zmud's [10] model has a clear organizational focus providing a framework to examine how employees may be encouraged to accept and fully use an IS. Applying a control perspective to this IS implementation model allowed us to consider the effect of formal controls on IS diffusion.

\section{Research method}

Guided by our research aim to explore how formal controls facilitate IS diffusion, we adopted a case study method. Case studies are particularly suitable when trying to answer the "how" and "why" questions of a research phenomenon [55]. Our case study followed the principles of "soft positivism" or "scientific realism" [22, 26], which enabled us to conduct the data analysis according to certain anticipations based on existing theory, but also allowed unexpected findings and explanations to emerge from the data, as in the manner of more interpretivist approaches. To this end, we developed a conceptual model from the literature, which was refined at the case site. As mentioned above, we used Cooper and Zmud's [10] six-stage IS implementation model to develop our framework and guide our data-collection efforts. We adopted an inductive analytical approach, which enabled us to expand on the preidentified constructs of Cooper and Zmud's [10] model and develop new findings. This approach helped us to produce a revised explanation that highlighted a more complex causal description of the formal controls exercised, as well as their impact on IS diffusion.

\subsection{Site selection}

Our research focus guided the selection of the case study site. We chose an organization that had recently implemented a management information system (MIS), and was thinking of putting formal control mechanisms in place to ensure that employees engaged with and used the system. This provided an opportunity to study how formal controls may facilitate the diffusion of a complex IS. The single-case study enabled us to make sense of our data without the risk of oversimplifying, and also to provide a rich description of the investigated phenomenon [44].

The organization we studied is a Nigerian multinational bank, which operates in 22 countries including the UK, France and the US and serves over seven million customers. In response to the bank's recognition of the need to implement technological innovations to assist its operations, an MIS called "MAXIM" was developed in-house by a dedicated management 
information (MI) team. MAXIM, a three-tiered software-architecture system, was intended to be a revolutionary tool, capable of accelerating the process of complex data analysis in order to generate sophisticated management reports.

\subsection{Data collection}

Before the fieldwork commenced, informal interviews via telephone and Skype were conducted with several managers to gain an understanding about the bank, its IS group and MAXIM. These informal interviews helped us identify informants who were well-placed to provide a wide range of views and experiences regarding the implementation and diffusion of the MIS and the application of formal controls. The informal interviews also highlighted that the IS, operations (OP) and finance (FI) groups stood to be directly affected by, and were the most likely beneficiaries of the implementation of MAXIM. Therefore, we targeted these three groups when seeking informants for interview, Informants were eventually chosen through a snowball sampling procedure [32].

Data collection took place in Nigeria between December 2010 and October 2012. MAXIM went live in October 2009 and had been in operation for over a year at the point data collection commenced. The first stage of data collection (December 2010) captured the views of employees during a period when MAXIM's diffusion had been unsuccessful with limited uptake and application of the system. This period provided data to classify the diffusion stage that MAXIM had achieved and provided a baseline for the attitudes and views held by employees toward the new MIS. The second stage of data collection (January to February 2011) captured the views of employees during a period when senior management began to apply strict formal control measures to ensure greater usage of MAXIM. This stage provided data to understand the rationale behind the choice of formal controls and how they would be applied. The third stage of data collection (March 2011 to June 2011) captured the experiences of employees and managers operating under the new control orientated regime for MAXIM. This stage revealed the effects of the application of the formal controls regarding the use of MAXIM and provided data that indicated that the MIS was being successfully assimilated into the organizational settings. In the first three stages of data collection, we collected three types of data: (1) face-to-face interviews; (2) observation data relating to informants' interaction with MAXIM and their non-MAXIM related activities; (3) review of relevant official documentation. (e.g., project documentation, emails, internal memos and content on the company's website) Finally, the fourth stage of data collection (July 2012 and September to October 2012) comprised of a series of follow up interviews to 
confirm the stage of diffusion that MAXIM had achieved and gather reflections on the impact of formal controls on the diffusion process. The follow-up interviews also provided an opportunity to clarify and further probe informants' earlier statements. The follow-up interviews were conducted via telephone, email and BlackBerry Messenger chat.

In the first three stages of data collection, a total of 47 individual semi-structured interviews were conducted (see Table 1). The interview questions centered on each informant's background, and their involvement in, understanding of, and experience with MAXIM. The interview questions also focused on how the informants perceived the history of the MIS project, individual and top-management roles and responsibilities, and control approaches. The duration of the interviews was between 35-70 minutes. The interviews were taperecorded with the informants' permission, and subsequently transcribed. The rationale for interviewing stakeholders from multiple organizational levels was twofold. First, it provided representativeness in the informants' descriptions of their experiences with MAXIM. Second, it allowed triangulation of data through comparing the views of stakeholders across different levels.

Table 1 Summary of interviews and participants (December 2010 - October 2012)

\begin{tabular}{lllll}
\hline Group & $\begin{array}{l}\text { Senior } \\
\text { management }\end{array}$ & $\begin{array}{l}\text { Middle } \\
\text { management }\end{array}$ & $\begin{array}{l}\text { Non-managerial } \\
\text { employees }\end{array}$ & Total \\
\hline Finance (FI) & $5(1)$ & $11(8)$ & $6(3)$ & $22(12)$ \\
$\begin{array}{l}\text { Operations (OP) } \\
\text { Information }\end{array}$ & $3(1)$ & $7(4)$ & $7(2)$ & $17(7)$ \\
systems (IS) & $3(2)$ & $3(2)$ & $2(1)$ & $8(5)$ \\
Total & $11(4)$ & $21(14)$ & $15(6)$ & $47(24)$ \\
\hline
\end{tabular}

Note: Numerals within brackets denotes follow-up interviews via telephone, email or via BlackBerry Messenger services within each informant category.

As noted above, the interviews were supplemented with multiple data sources including observations of informants while they engaged with MAXIM, project documentation, emails, internal memos and company website information. This enabled triangulation and the establishment of construct validity and gave richness to the findings [55]. During the analysis of the interviews, it became evident that the need to acquire a suitable MIS, and the justification for adopting the MIS had occurred four years prior to the data-collection period. In Cooper and Zmud's [10] terms, these activities represented the initiation and adoption 
stages of the diffusion model. Therefore, in order to reduce reliance on retrospective data and the risk of inaccurate recollections and post-hoc rationalization, the fieldwork focused on the events and activities of the MIS implementation that were either still occurring, or had most recently been completed. Further, when the data collection was drawing to a close, MAXIM had not yet been fully utilized in a comprehensive way to enhance overall organizational efficiency. Such activities characterize the final infusion stage of Cooper and Zmud's [10] diffusion model. Thus, this study could not investigate the impact of formal controls in the infusion stage. In sum, this study focused on investigating the experiences of employees using MAXIM during periods which broadly corresponded with the 'adaptation', 'acceptance' and 'routinization' stages of Cooper and Zmud's [10] six-stage IS implementation model.

\subsection{Data analysis}

Once the fieldwork was completed, following the procedure recommended by Miles and Huberman [27], we closely examined the data collected to look for control mechanisms that influenced the adaptation and acceptance of MAXIM. There was no strong evidence of an application of informal control mechanisms, but formal controls, such as behavior and outcome control mechanisms, were striking. Therefore, we examined in greater detail how these formal controls were exercised during the MAXIM implementation.

In order to examine the impact of these formal controls on the diffusion of MAXIM, we needed to understand employee attitudes toward the mechanisms put in place by the senior management to ensure employees engaged with, and used, MAXIM. To this end, we read the interview transcripts several times, coding statements that best described informants' views, attitudes and relationships toward MAXIM during the implementation process. From this coding procedure several common themes were identified regarding the application of formal control mechanisms associated with the use of MAXIM. Examples of themes identified include: employee resistance to MAXIM; behavior control mechanisms; outcome control mechanisms; employees' reactions to control mechanisms; and implications of formal controls on MAXIM diffusion (Appendix 1 explains our data analysis process in greater detail).

We analyzed the data in several iterations to establish whether it supported our initial framework. This included an evaluation of the degrees of consensus and consistency among informants in relation to their interpretations of MAXIM's implementation, and the 
implications of the applied control mechanisms on the implementation process. Finally, we reassessed the data to connect the themes, thereby facilitating a) the discovery of rich insights into the effects of formal controls on the diffusion process and b) the development of a revised explanation of the IS diffusion process.

\section{Findings}

In this section, we describe the formal controls exercised by the bank's senior management during the implementation of MAXIM, and the impact of these formal controls on diffusion.

\subsection{MAXIM implementation: April 2008 - December 2010}

In April 2008, the bank drew on inputs from the existing legacy systems and began the design, development and installation of MAXIM. In order to adapt MAXIM to their requirements, the OP and FI groups worked with the IS Group to design MAXIM's end-user modules. By July 2009, the adaptation of MAXIM was deemed to have been completed; however, there were several unresolved conflicts between the IS group and the OP/FI groups when configuring the end-user modules. The OP and FI groups complained that the IS group had not fully understood their requirements. For instance:

IS have their own mappings, their belief is that reports should not be based on a single product; [they] should be based on grouping the products. We have to make IS understand that will not work for us, so they have to look for a way around it. That is the reason why we are not fully using it. (E-retail executive, OP group)

The conflicts usually stemmed from disagreements about whether the business terms and functionalities supported by MAXIM truly reflected the everyday needs of the OP and FI groups. Although some of the employees in these two groups were willing to work with the system, many were skeptical about whether MAXIM had been adapted well-enough to meet their needs. In this sense, we would argue that the adaptation of MAXIM to the end-user's requirements was only partial.

MAXIM was rolled out and introduced to the OP and FI groups in August 2009 through a series of training programs and awareness and promotional campaigns. MAXIM was supposed to replace an existing MIS called INFOPOOL as well reduce the over-reliance on the use of Microsoft Excel spreadsheets for data analysis. However, there was clear evidence that many in the OP and FI groups did not value the system, and resisted it when it was first implemented. By November 2010, only a few employees were using MAXIM extensively. 
Although many employees did use MAXIM for data extraction purposes, they invariably turned to the more familiar Excel software for data analysis. It was clear that many employees did not believe that the system would improve their productivity levels and hence, they did not use MAXIM as part of their work routine. In terms of Cooper and Zmud's [10] diffusion model, we may thus term this phase of the implementation as resulting only in partial acceptance and partial routinization. In response to the high levels of resistance and the poor progress of the MAXIM project, the senior management began implementing a series of formal control mechanisms to force the OP and FI groups to engage better with MAXIM.

\subsection{Formal control measures and MAXIM implementation: January-June 2011}

\subsubsection{Adaptation}

Between January-June 2011 senior managers took two specific actions to change the resisting attitudes and behaviors of the OP and FI groups in relation to MAXIM. These actions corresponded closely with what the literature has termed as behavioral control modes. First, senior managers attended several of the MAXIM training sessions, which were organized for employees. This enabled them to gauge employees' experiences of using MAXIM, and the problems employees were encountering in adapting and aligning their everyday activities in line with MAXIM's offerings. More importantly, the presence of senior managers in the training programs sent out a clear message to the resisting employees: MAXIM had the backing of senior managers and employees were expected to change their resisting behaviors and embrace the system.

Second, a meeting of all the managers in the IS, OP and FI groups was called to address the ongoing disagreements and conflicts in relation to MAXIM. The main objective of the meeting was to explain that MAXIM was now an integral part of the bank and that senior management wanted the groups to engage extensively with the system. It was made clear to the managers in the IS group that it was their responsibility to customize the various modules in MAXIM, as best as the design would allow, to the requirements of the OP and FI groups. Similarly, managers in the OP and FI groups were told in no uncertain terms that they had to adapt to the new system and that they had to work with the IS group in a spirit of 'give and take'. Broadly, senior managers emphasized in the meeting that differences had to be set aside, and that the groups had no choice but to work together cohesively to ensure that MAXIM was implemented smoothly: 
We had a stakeholder meeting at the very top and the OP and FI groups were asked to merge with MAXIM and nobody can say 'no' when senior management asks you to ... If the one that you do not want to use (i.e. MAXIM) has some unexpected features in relation to the one you are used to (i.e. INFOPOOL), then you will merge the data... this is what happened ... management decided that they wanted to see everything from MAXIM. (Senior programmer, IS group)

\subsubsection{Acceptance}

Senior managers employed a further set of mechanisms to improve MAXIM's acceptance levels within the OP and FI groups. Given that they required employees to produce timebased outputs, these mechanisms could be viewed as good illustrations of outcome control modes at play [see 7]. When employees were assigned the task of producing management reports, they were given strict deadlines based on the amount of time senior management felt was enough to produce the reports via MAXIM. For example, the FI group was given a strict deadline (i.e. 20 minutes) to complete a particularly complex dynamic analysis of the bank's current financial strength. FI group employees realized quickly that they could not complete the job within the specified timeframe by using a non-MAXIM based approach. In other words, they were forced to use MAXIM to meet the deadlines set by senior management.

... nobody is doing any manual [work] ... because most of our bosses are aware via their attendance of MAXIM workshops that using the new system is faster [than] existing processes ... They tell you [you] can get it done in 20 minutes and it can take hours if you are doing it manually, so there will be a problem for you ... so people are complying. (Balance sheet \& Market risk management analyst, FI group)

Senior managers also kept a very close watch on the daily reports generated by the OP and FI groups. They scrutinized usage and audit trail reports to find out whether employees were actually using MAXIM extensively. This monitoring seemed to lead to increased use of MAXIM. There was a sharp rise in the number of requests from the OP and FI groups to the IS group to further automate particular processes in MAXIM:

Senior management have an eye on the monthly dashboard report that comes out of MAXIM. People are really using [MAXIM] now. This has been corroborated by the audit people, an independent group within the bank that monitor's MAXIM usage. (Group head, IS group)

\subsubsection{Routinization}

Despite the increased use of MAXIM, resistance had continued in some parts of the OP and FI groups. Some employees in the OP and FI groups still employed other manual processes and blamed the system for not performing to expectations. Senior management felt that such 
complaints were unwarranted excuses to justify the use of pre-MAXIM methods of generating and analyzing data. With a view to embed and routinize the use of MAXIM, senior management intensified the application of formal controls (both behavior and outcome controls). They issued strict directives (via internal memos and emails) to abandon working practices and procedures from the pre-MAXIM days. To avoid any ambiguity, these directives referred to specific practices such as the use of legacy MIS and Excel spreadsheets. The IS group was asked to not respond to requests that required the generation of reports from the bank's legacy financial systems. Only requests that could be actioned through MAXIM were allowed:

[It was] a directive [received] through emails and memos that all other source of other applications like INFOPOOL [legacy system] and Excel used for financials should be stopped, that nobody should use [these] again and they should all be using MAXIM. (Head of Financial Subsidiaries, FI group)

To underline the mandatory use of MAXIM, senior management continued to issue deadlines as a form of outcome control [see 7, 23]. For example, a clear timetable (with a rigid deadline) was set out for the changeover from existing data analysis processes to MAXIMbased data analytics. This timetable compelled the OP and FI groups to work closely with the IS group to resolve all issues in the design and implementation of MAXIM. Employees were told that after the deadline, they would no longer have access to alternative systems, and that only MAXIM would be available to analyze data and generate management reports:

We were given a timeline to stop the use of other processes and there was a cutoff [date] for other applications that we previously used to provide that kind of information. So you had no choice but to learn to use MAXIM effectively to produce your reports. Otherwise your KPIs could be affected. (Product manager, OP group)

The resolve of senior management to enforce the "MAXIM-only" policy was clearly demonstrated by the Head of Financial subsidiaries (FI group), who recalled trying to produce a report from MAXIM to a tight deadline and eventually switching back to old methods in an attempt to meet the deadline. However, despite generating the report on time, it was not accepted and his team was required to complete the task using MAXIM, which meant missing the deadline. This experience served as a reminder to other employees as well that even if processes now took longer using MAXIM they would not be allowed to return to old ways of working: 
It was forced. There was a time that we produced a report for the executive director of finance, [and] he rejected the manual account because he had mandated we use MAXIM for that month. We were trying, but felt we couldn't finish it by the end of the month and so we switched to the use of Excel. But the executive director refused to take it from us. Eventually we got it done [using MAXIM]. When we were through with it he said, 'next month I want to see another, progress further. I want more from MAXIM.' So we went back and continued until we got to the stage we are today. So I will say it [was forced] but now people are now enjoying it [so] we needed that force. (Head of Financial subsidiaries, FI group)

Informants also explained that they adhered to the strict directive to engage with MAXIM because of a fear of being reprimanded by senior management:

You could be sanctioned according to policy ... suspension or even dismissal for lack of productivity. (Senior credit analyst, FI group)

You have to follow the prescribed guidelines to process your transaction, which can only be done on MAXIM. So there could be sanctions if you do not use MAXIM, sanctions such as queries, suspension, etc. (Business operations executive, OP group)

The above quotes suggest that senior managers implicitly raised the possibility of punishment and sanctions in cases where employees did not use MAXIM. Although there was no evidence that employees were actually punished for non-compliance, it appeared that the fear of being punished was sufficient to ensure the routine use of MAXIM. It was also noteworthy that despite hinting at a sanctions system, senior managers did not implement a clear rewards system. In fact it was made clear that the use of MAXIM would not lead to rewards. Employees were told that routine use of MAXIM was a part of their job, and that there was no need to acknowledge or appreciate their use of the system, or provide any extrinsic motivations or incentives to do so.

No there is no reward, since I have started using it nothing has changed, no reward except for the fact that it simplifies my work. (Analyst, FI group)

\subsection{Impact of formal controls on MAXIM diffusion}

By the end of our data collection in June 2011, it was clear that the formal controls, which made MAXIM mandatory, were successful in overcoming the initial user resistance, and facilitating the diffusion of the system. In particular, the possibility of sanctions for nonusage, combined with senior managers' decision to only accept MAXIM-generated reports, forced employees to use MAXIM to complete their work. Interestingly, several informants 
acknowledged that this push from senior management had been the major driver for the system's eventual acceptance and routinization. Several informants acknowledged that while they initially felt uncomfortable about using only MAXIM, they did not resent the control measures. The formal controls had ultimately proved beneficial to themselves, and to the functioning of the bank as a whole. They had become more familiar with MAXIM, and through increased use, were finding additional benefits and opportunities. Table 2 summarizes the various control mechanisms deployed to overcome user resistance during the implementation of MAXIM.

It enhanced the learning process because earlier...some people were being negligent. They never took MAXIM seriously, probably had there not been such actions from senior management, some [would] still say I don't trust it, [and] not bother to push further in understanding the system, but with the measures put in by senior management, we all fully migrated to the use of MAXIM and we rely on it now. (Head of Liga trustees, FI group)

The measures have worked well. I believe it was an effective way and also a good way of doing things because it [made] everyone fully use MAXIM to perform their daily functions to achieve a high level of performance. (e-Channels administrator, OP group)

Table 2 Control mechanisms applied to overcome user resistance during MAXIM implementation

\begin{tabular}{|c|c|c|}
\hline $\begin{array}{l}\text { Diffusion } \\
\text { Stage }\end{array}$ & Control mechanisms & $\begin{array}{l}\text { Control } \\
\text { mode }\end{array}$ \\
\hline Adaptation & $\begin{array}{l}\text { Senior management organized and monitored training sessions to review } \\
\text { usage of MAXIM [21] } \\
\text { Senior management organized stakeholder meetings to ensure that the } \\
\text { OP and FI groups worked effectively with the IS group to prepare } \\
\text { MAXIM for organizational use [20] }\end{array}$ & Behavior \\
\hline Acceptance & $\begin{array}{l}\text { Senior management issued specific timelines/deadlines for employees to } \\
\text { produce reports that could only be achieved by using MAXIM [20, 23, } \\
\text { 29] } \\
\text { Senior management evaluated reports generated from MAXIM [7, 21] }\end{array}$ & Outcome \\
\hline & $\begin{array}{l}\text { Senior management issued strict directives to abandon the previous } \\
\text { methods utilized to generate information [14] }\end{array}$ & Behavior \\
\hline Routinization & $\begin{array}{l}\text { Senior management issued non-negotiable timelines/deadlines to change } \\
\text { over to the use of MAXIM }[20,23,29] \\
\text { Senior management continued to evaluate the reports generated from } \\
\text { MAXIM }[7,21]\end{array}$ & Outcome \\
\hline
\end{tabular}




\section{Discussion}

Our findings, described above, highlight how the implementation of MAXIM faced an initial extended period of difficulties due to many employees in the OP and FI groups remaining disengaged with the system. Senior management had hoped a series of positive outcomes would be achieved during this period for the system's diffusion. In theoretical terms their expectations for this period resonated with what Cooper and Zmud [10] have termed as the adaptation, acceptance and routinization stages of diffusion. However, in reality, there were only a few positives with many employees choosing not to use MAXIM. Therefore, we might refer to this period prior to the imposition of formal controls as having gone through a sequential process of partial adaptation, partial acceptance and partial routinization. This is depicted in Figure 2 below. It is worth noting that there was no feedback between the partial adaptation and partial acceptance stages because it was only during the partial routinization stage that the senior management realized that MAXIM's diffusion had stalled due to user resistance.

Having recognized that the system's diffusion had stopped, senior management applied strict formal controls to ensure that users interacted positively with MAXIM. In other words, formal controls were applied only after it became clear that MAXIM had only been partially routinized within the bank. These controls were applied to facilitate higher levels of adaptation and then subsequently acceptance and routinization of MAXIM. Figure 2 describes and synthesizes these findings. It also helps answer our first research question which sought to address how and when formal controls are applied during the organizational diffusion of an IS. Our findings suggest that even in large scale MIS projects, strict formal control mechanisms may only be applied as an afterthought or as a response to a failing course of action. It might therefore be useful to (a) analytically separate control mechanisms and stages of IS diffusion, and (b) closely examine the level of formal controls exercised at different stages of a planned IS diffusion process and their impact on end-user behavior, bearing in mind that these different stages may not necessarily map-on directly to established theoretical models. Figure 2 further shows how 'time' can be a crucial element in evaluations of IS diffusion outputs. For instance, if we were to only consider the MAXIM case until partial routinization, we may arrive at the reasonable (but erroneous) conclusion that high levels of diffusion was not achieved in the MAXIM project, especially since it had already taken more than 2.5 years to reach this stage. However, as subsequent events demonstrated, 

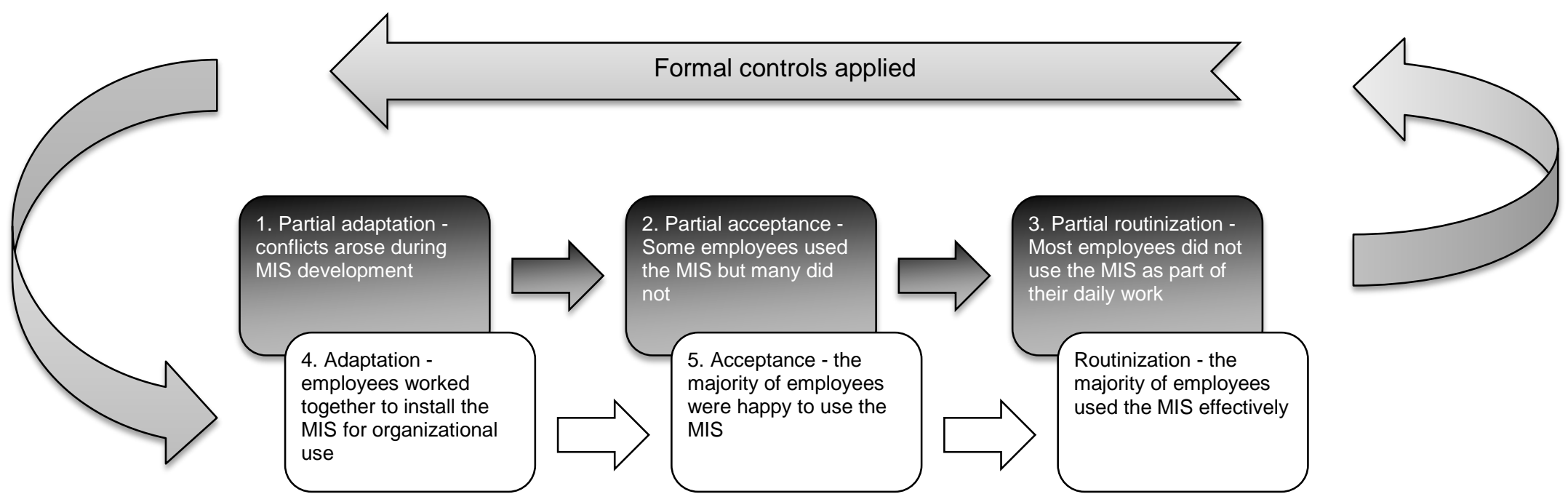

Figure 2 Application of formal controls to achieve MIS diffusion at the bank 
the application of formal controls did facilitate a fuller diffusion of MAXIM. This insight not only emphasizes the virtues of longitudinal research, but also draws attention to the important relationship between the long-term continuity of an IS project and its performance [see 41].

Our second research question investigated the consequences of applying formal controls to the process of IS diffusion. The findings revealed that a combination of behavior control mechanisms (training sessions and meetings) and outcome control mechanisms (specific timelines/deadlines and monitoring of MIS outputs) allowed existing user practices to be aligned with system procedures, that in turn ensured that only desirable user actions occurred during the IS implementation. This is consistent with prior research that has studied how different control mechanisms in organizations can be applied to achieve successful implementation and alignment with business requirements of an organization-wide IS [21]. For example, Kirsch et al. [23] highlighted that clients can use formal control mechanisms, such as scheduling, to specify to project leaders how to achieve systems development. Our data suggest that deliberate attempts by senior management to exercise control measures, forced employees to engage with and use a complex IS, thereby facilitating the diffusion of the MIS. This controlled implementation process was unlike a voluntary setting in which users could control their own behavior, or were permitted to use the system only rarely, which would have led to users not possessing the required knowledge to utilize the system in an effective and efficient way [17]. Thus, the findings from our study indicate that the application of formal controls can facilitate the diffusion of an IS in an organization.

Kirsch [22] argued that as the implementation process of an IS project evolves, trust develops among the different stakeholders, resulting in the replacement of formal control mechanisms with informal ones. Thus, in our case after the application of formal controls and as MAXIM proceeded to be diffused into the bank, the well-ordered prescribed relationship between the controllers and controlees should have evolved into more cordial and trustworthy relations, prompting a possible change from formal control mechanisms to informal ones. However, this was not what happened during the diffusion of MAXIM. We suggest that our findings differ to those of Kirsch [22] since in our case users had resisted MAXIM when it was first implemented (August 2008 - December 2010). Consequently, senior management may not have trusted users to engage with the system without strict formal controls in a manner that would facilitate successful diffusion. This could be one possible explanation for why senior management chose not to apply informal controls. 
The findings reveal that the successful implementation and diffusion of an IS may be an iterative rather than sequential process [16]. Taking a situated learning perspective, Wagner and Newell [49] suggest that the post-implementation stage of enterprise software (ES) projects could be iterative in nature, due to user-developer participation in learning how to exploit the functionality of the ES. Arguably, if there were a lack of user-developer participation or technology resistance during the post-implementation stage the iteration process could be slow and ineffective. Our study makes a useful contribution to this debate demonstrating that the application of formal controls can help to bridge the user-ISdeveloper gap, and also align user actions with use of the MIS thereby enabling successful diffusion.

A further important contribution from our study concerns the use of reward and sanction procedures. Existing literature shows how formal controls frequently feature reward and sanction procedures in tandem to motivate controlees to comply with polices and guidelines [22, 25, 35]. Liang et al. [25] report that sanction expectancy is more effective than reward expectancy for effective application of controls. Our study extends existing literature and suggests that the application of formal controls with clearly defined sanctions, but no formal rewards, can also be effective in achieving IS diffusion. In other words, in our study senior managers in the bank used the 'stick' without the 'carrot' to achieve widespread acceptance of the MIS. Previously, we may have thought that such a draconian approach would have been met with increased user resistance rather than higher levels of acceptance. However, the findings of our study indicate that this is not always the case. Achieving higher familiarity with an IS, albeit under mandatory use conditions, can help to push users to commit and fully understand a new system thereby moving from resistance to acceptance. Thus, our study makes an important contribution to knowledge providing empirical evidence that suggests that reward and sanction procedures associated with formal control mechanisms do not have to be used in tandem to achieve IS diffusion.

The success of the formal control mechanisms also draws attention to the role played by a more basic emotion - fear - in IS diffusion. From a psychological perspective one could argue that the formal control mechanisms were very effective in this context because many employees were scared of annoying their senior managers, and feared that they (employees) might lose their jobs if they did not use the MIS. In this sense, our study highlights the crucial nexus between control mechanisms and fear as a driver of IS diffusion in some contexts. 


\section{Conclusion}

This study has utilized case study research to examine how and why formal controls facilitated the diffusion of a complex IS. Implications for IS diffusion, theory and practice are discussed below.

IS scholars have called for further research on IS diffusion [53] and in particular on IS implementations under mandatory conditions, and the impact these conditions can have on IS implementation [17]. This study responds to this call and provides fresh evidence to show that the application of formal controls can overcome user resistance and enable successful IS diffusion. Further, our study provides evidence to indicate that the IS diffusion process may be iterative after systems go live. This evidence is in contrast to existing knowledge which describes the diffusion process as linear and sequential [10,39]. These contributions are important because they could provide strategies for managers to achieve successful IS diffusion and a return on their IS investment.

Our study also contributes to theory regarding the application of formal controls. Existing control studies advocate that controllers must use clear reward and sanction procedures in tandem in order to motivate controlees to comply with polices and guidelines [e.g. 22, 25]. Our case study had no evidence of reward procedures and showed that sanction expectancy alone could facilitate enhanced usage of an IS. Thus, our study provides evidence to suggest that users' fear of sanction maybe sufficient without reward expectancy for IS acceptance and routinization.

Finally, we contribute to IS practice by proposing that organizations that desire enhanced IS usage and IS diffusion should consider putting strict policies in place to sanction noncompliant usage of the IS. This is important as most organizations prefer to stress the importance of garnering user commitment rather than resorting to punishment practices [52]. However, if senior managers choose to adopt a mandatory approach to IS usage through the application of formal control mechanisms it is important that a creditable coercive message is conveyed with suitable punishment mechanisms in place. If the perceived threats of not complying with the new IS are less than the threats from using the new IS, then user resistance may increase [40]. Further, for such punishment policies to be effective they need to applied with fairness and perceived justice. Senior managers need to explain why punishment actions are being taken, and offer advice on the required usage practices to avoid future punishment. Otherwise there is a risk that the application of punishment policies could 
be seen as unjust, leading to a vicious circle of increasing user discontent and noncompliance, undermining the goal of strict sanction polices [54].

Although our study makes some important contributions, it is subject to a number of limitations. First, while adopting a single-case method provides deep insights and increases the representativeness of the views of informants regarding IS diffusion, it limits generalizability [52]. However, in our study we have attempted to generalize from empirical statements to theoretical statements and thereby achieve a degree of analytical generalizability [24]. Second, we must acknowledge that our study did not assess the longterm strategic benefits of the diffused MIS. While we have focused narrowly on the role of formal controls in IS diffusion in this paper, future research also needs to look deeper into the extent to which diffused systems deliver positive strategic outcomes. Third, our focus on formal controls may have ignored the role of some bottom-up drivers in the IS diffusion process. For example, the OP and FI groups could have developed a positive and advanced 'IT culture' [51] over time, which may explain their increased engagement with MAXIM. Further research is required to assess the impact of such forces on IS diffusion. Lastly, because the MIS had not achieved the infusion stage of diffusion at the end of data collection, our case study is limited in making claims about the possible application of informal controls (such as self and clan control) in the final stages of IS diffusion. Informal controls at this point may help to facilitate higher levels of user ownership, a requirement for attaining higher organizational efficiencies [9]. Future studies could try to determine whether a combination of informal controls should be applied for the final stages of the diffusion process.

\section{Acknowledgements}

We offer sincere thanks to Sue Newell, Carole Tansley and Richard Baskerville for their helpful comments and guidance. 


\section{References}

[1] Bartis, E., Mitev, N. (2008). A multiple narrative approach to information systems failure: a successful system that failed. European Journal of Information Systems, 17, 112124.

[2] Boudreau, M., Robey, D. (2005). Enacting integrated information technology: A human agency perspective. Organization Science, 16(1), 3-18.

[3] Brown, S. A., Dennis, A. R., Venkatesh, V. (2010). Predicting Collaboration Technology Use: Integrating Technology Adoption and Collaboration Research. Journal of Management Information Systems, 27(2), 9-53.

[4] Brown, S. A., Massey, A. P., Montoya-Weiss, M. M., Burkman, J. R. (2002). Do I really have to? User acceptance of mandated technology. European Journal of Information Systems, 11(4), 283-295.

[5] Cabrera, A., Cabrera, E. F., Barajas, S. (2001). The key role of organizational culture in a multi-system view of technology-driven change. International Journal of Information Management, 21(3), 245-61.

[6] Cavusoglu, H., Hu, N., Li, Y., Ma, D. (2010). Information Technology Diffusion with Influentials, Imitators, and Opponents. Journal of Management Information Systems, 27(2), 305-334.

[7] Choudhury, V., Sabherwal, R. (2003). Portfolios of Control in Outsourced Software Development Projects. Information Systems Research, 14(3), 291-314.

[8] Chua, C., Lim, W. K., Soh, C., Sia, S. K. (2012). Enacting Clan Control in Complex IT Projects: A Social Capital Perspective. MIS Quarterly, 36(2), 577-600.

[9] Coombs, CR, Doherty, NF, Loan Clarke, J (2001) The Importance of User Ownership and Positive User Attitudes in the Successful Adoption of Community Information Systems, Journal of End User Computing, 13(4), 5-16.

[10] Cooper, R., Zmud, R. (1990). Information Technology Implementation Research: A Technological Diffusion Approach. Management Science, 36(2), 123-139.

[11] Davidson, E., Chiasson, M. (2005). Contextual influences on technology use mediation: a comparative analysis of electronic medical record systems. European Journal of Information Systems, 14(1), 6-18.

[12] Davis, F. D. (1989). Perceived usefulness, perceived ease of use, and user acceptance of information technology. MIS Quarterly, 13(3), 319-340.

[13] DeLone, W. H., E. R. McLean (2003) The Delone And Mclean Model Of Information Systems Success: A Ten Years Update, Journal of Management Information Systems 19(4), 9-30.

[14] Eisenhardt, K. M. (1985). Control: Organizational and economic approaches. Management Science, 31(2), 134-149.

[15] Gable, G. G., Sedera, D., \& Chan, T. (2008). Re-conceptualizing information system success: the IS-impact measurement model. Journal of the Association for Information Systems, 9(7), 377-408.

[16] Galliers, R. D., Swan, J. (1999). Information systems and strategic change: a critical review of business process re-engineering. In W. L. Currie, \& R. Galliers, (Eds), Rethinking Management Information Systems (pp. 361-87). Oxford: Oxford University Press.

[17] Hsieh, J. J. P., Wang, W. (2007). Explaining employees' Extended use of complex Information Systems. European Journal of Information Systems, 16, 216-217.

[18] Jasperson, J., Carter, P., Zmud, R. (2005). A Comprehensive Conceptualization of Post-Adoptive Behaviors Associated with Information Technology Enabled Work Systems. MIS Quarterly, 29(3), 525-557.

[19] Jaworski, B. J. (1988). Toward a Theory of Marketing Control: Environmental Context, Control Types, and Consequences. Journal of Marketing, 52(3), 23-39. 
[20] Kirsch, L. J. (1996). The Management of Complex Tasks in Organizations: Controlling the Systems Development Process. Organization Science, 7(1), 1-21.

[21] Kirsch, L. J. (1997). Portfolios of control modes and IS project management. Information Systems Research, 8(3), 215-239.

[22] Kirsch, L. J. (2004). Deploying Common Systems Globally: The Dynamics of Control. Information Systems Research, 15(4), 374-395.

[23] Kirsch, L. J., Sambamurthy, V. K. D., Purvis, R. (2002). Controlling information systems development projects: View from the client. Management Science, 48(4), 484-498.

[24] Lee, A. S., Baskerville, R. L. (2003). Generalizing Generalizability in Information Systems Research, Information Systems Research, 14(3), 221-243.

[25] Liang, H., Xue, Y., Wu, L. (2013). Ensuring Employees' IT Compliance: Carrot or Stick? Information Systems Research, 24(2), 279-294.

[26] Madill, A., Jordan, A., Shirley, C. (2000). Objectivity and reliability in qualitative analysis: realist, contextualist and radical constructionist epistemologies. British Journal of Psychology, 91(1), 1-20.

[27] Miles, M. B., Huberman, A. M. (1994). Qualitative Data Analysis: An Expanded Sourcebook. London: Sage Publications.

[28] Newell, S., Tansley, C., Huang, J. C. (2004). Social Capital and Knowledge Integration in an ERP Project Team: The Importance of Bridging and Bonding. British Journal of Management, 15(S1), S43-S57.

[29] Orlikowski, W. J. (1991). Integrated information environment or matrix of control? The contradictory implications of information technology. Accounting, Management and Information Technologies, 1(1), 9-42.

[30] Orlikowski, W. J., Yates, J., Okamura, K., Fujimoto, M. (1995). Shaping electronic communication: the metastructuring of technology in the context of use. Organization Science 6(4), 423-444.

[31] Ouchi, W. G. (1979). A Conceptual Framework for the Design of Organizational Control Mechanisms. Management Science, 25(9), 833-848.

[32] Patton, M. Q. (2002). Qualitative Research and Evaluation Methods. California: Sage Publications.

[33] Petter, S., McLean, E.R. (2009). A meta-analytic assessment of the DeLone and McLean IS success model: An examination of IS success at the individual level. Information \& Management, 46(3) 159-166.

[34] Petter, S., DeLone, W. McLean, E.R., (2013). Information Systems Success: The Quest for the Independent Variables. Journal of Management Information Systems, 29(4), 762.

[35] Ravishankar, M.N. (2008). Rewarding end-users for participating in organizational KM: A case study, Journal of Organizational and End User Computing, 20(1), 35-49.

[36] Ravishankar, M. N., Pan, S. L., Leidner, D. E. (2011). Examining the strategic alignment and implementation success of a KMS: A subculture based multi-level analysis. Information Systems Research, 22(1), 39-59.

[37] Robey, D., Ross, J. W., Boudreau, M. C. (2002). Learning to Implement Enterprise Systems: An Exploratory Study of the Dialectics of Change. Journal of Management Information Systems, 19(1), 17-46.

[38] Rogers, E. M. (1995). Diffusion of Innovations. New York: Free Press.

[39] Rothwell, R. (1994). Towards the Fifth-generation Innovation Process. International Marketing Review, 11(1), 7-31.

[40] Rivard, S., Lapointe, L. (2012) Information Technology Implementers’ Responses to User Resistance: Nature and Effects. MIS Quarterly, 36(3), 897-920. 
[41] Sandeep, MS and Ravishankar, MN (2014) The continuity of underperforming ICT projects in the public sector, Information and Management, 51(6), 700-711.

[42] Seddon, P. B., Kiew, M.Y. (1996) A partial test and development of DeLone and McLean's model of IS success, Australian Journal of Information Systems, 4(1), 90-109.

[43] Sharma, R., Yetton, P. (2003). The contingent effects of management support and task interdependence on successful information systems implementation, MIS Quarterly 533556.

[44] Siggelkow, N. (2007). Persuasion with case studies. Academy of Management Journal, 50, 20-24.

[45] Sundaram, S., Schwarz, A., Jones, E., Chin, W. W. (2007). Technology Use on the Front Line: A Longitudinal Analysis of How Technology Enhances Individual Performance. Journal of the Academy of Marketing Sciences, 35, 101-112

[46] Tate, M., Sedera, D., McLean, E., Burton-Jones, A. (2014) Information systems success research: the "Twenty Year Update?" panel report from PACIS, 2011. Communications of the Association for Information Systems, 34(64): 1235-1246.

[47] Venkatesh, V., Morris, M. G., Davis, G. B., Davis, F. (2003). User acceptance of information technology: Toward a unified view. MIS Quarterly, 27(3), 425-478.

[48] Venkatesh, V., Thong, J.Y.L., Chan, F.K.Y., Hu, P.J-H., Brown, S.A. (2011) Extending the Two-stage Information Systems Continuance Model: Incorporating UTAUT Predictors and the Role of Context, Information Systems Journal, 21(6), 527-555.

[49] Wagner, E., Newell, S. (2007). Exploring the importance of participation in the postimplementation period of an ES project: A neglected area. Journal of the AIS, 8(10), 508524.

[50] Wagner, E., Newell, S. (2011). Changing the Story Surrounding Enterprise Systems. In R. Galliers, \& W. L. Currie, (Eds), The Oxford Handbook of Management Information Systems: Critical Perspectives and New Directions (pp. 394-414). Oxford: Oxford University Press.

[51] Walsh, I., Kefi, H. and Baskerville, R. (2010). Managing Culture Creep: Toward a strategic model of user IT culture. Journal of Strategic Information Systems, 19(4), 257-280

[52] Walsham, G. (1995). Interpretive case studies in IS research: nature and method. European Journal of Information Systems, 4(2), 74-81.

[53] Williams, M. D., Dwivedi, Y. K., Lal, B., Schwarz, A. (2009). Contemporary trends and issues in IT adoption and diffusion research. Journal of Information Technology, 24(1), $1-10$.

[54] Xue, Y., Liang, H., Wu, L. (2011). Punishment, Justice, and Compliance in Mandatory IT Settings. Information Systems Research, 22(2), 400-414.

[55] Yin, R. K. (2009). Case study research: Design and methods. California: Sage Publications. 
Appendix 1. Data analysis: Representative quotes, codes and themes

\begin{tabular}{|c|c|c|}
\hline Representative Quotes & Codes & Theme \\
\hline $\begin{array}{l}\text { No, we did not engage with MAXIM straight away because we did } \\
\text { not have the level of confidence required to use a foreign 'thing' } \\
\text { (...) because anything new coming from outside we want to know } \\
\text { whether it will produce the same results with the previous methods } \\
\text { we have been using. (Credit Analyst, FI Group) }\end{array}$ & $\begin{array}{l}\text { Suspicion of } \\
\text { new system }\end{array}$ & \multirow{2}{*}{$\begin{array}{l}\text { Employee } \\
\text { resistance to } \\
\text { MAXIM } \\
\text { implementation }\end{array}$} \\
\hline $\begin{array}{l}\text { IS have their own mappings, their belief is that reports should not } \\
\text { be based on a single product; [they] should be based on grouping } \\
\text { of the products. We have to make IS understand that will not work } \\
\text { for us, so they have to look for a way around it. That is the reason } \\
\text { why we are not fully using it. (e-Retail executive, OP Group) }\end{array}$ & $\begin{array}{l}\text { Lack of } \\
\text { empathy with } \\
\text { business needs }\end{array}$ & \\
\hline $\begin{array}{l}\text { The Group Managing Director came to scheduled training sessions } \\
\text { to check users' view of MAXIM. It was [showing] that management } \\
\text { is behind it [MAXIM] to make sure that users were using MAXIM. } \\
\text { (Database Administrator, IS Group) }\end{array}$ & $\begin{array}{l}\text { Training and } \\
\text { awareness } \\
\text { campaigns }\end{array}$ & \multirow{2}{*}{$\begin{array}{l}\text { Behavior control } \\
\text { mechanisms }\end{array}$} \\
\hline $\begin{array}{l}\text { In January 2011, we had a stakeholder meeting at the very top and } \\
\text { the OP and FI groups were asked to merge with MAXIM and } \\
\text { nobody can say 'no' when senior management asks you to ... } \\
\text { (Senior programmer, IS Group) }\end{array}$ & $\begin{array}{l}\text { Specifying } \\
\text { rules and } \\
\text { procedures for } \\
\text { MAXIM use }\end{array}$ & \\
\hline $\begin{array}{l}\text { We were given a timeline to stop the use of other processes and } \\
\text { there was a cut-off [date] for other applications that we previously } \\
\text { used to provide that kind of information. So you had no choice but } \\
\text { to use MAXIM effectively to produce your reports. Otherwise your } \\
\text { KPI could be affected. (Product manager, OP Group) }\end{array}$ & $\begin{array}{l}\text { Timelines/ } \\
\text { Schedule }\end{array}$ & \multirow[t]{2}{*}{$\begin{array}{l}\text { Outcome control } \\
\text { mechanisms }\end{array}$} \\
\hline $\begin{array}{l}\text { The fact that we know that somebody somewhere is monitoring our } \\
\text { activities on MAXIM prompts us to use the system. (Business } \\
\text { Operations Executive, OP Group) }\end{array}$ & $\begin{array}{l}\text { Monitoring/ } \\
\text { MAXIM } \\
\text { Outputs }\end{array}$ & \\
\hline $\begin{array}{l}\text { You have to follow the prescribed guideline to process your } \\
\text { transaction, which can only be done on MAXIM. So there could be } \\
\text { sanctions if you do not use MAXIM, sanctions such as queries, } \\
\text { suspension etc. (Business operations executive, OP Group) }\end{array}$ & $\begin{array}{l}\text { Query/ } \\
\text { Suspension/ } \\
\text { Dismissal }\end{array}$ & \multirow{2}{*}{$\begin{array}{l}\text { Sanctions for non } \\
\text {-compliance with } \\
\text { controls }\end{array}$} \\
\hline $\begin{array}{l}\text { Oh yes, serious sanctions, like a query and in extreme cases, one } \\
\text { can be given various substantial measures like suspension. Non- } \\
\text { usage of MAXIM can affect your deliverables; consequently it will } \\
\text { affect your appraisals and ultimately affect your employment. } \\
\text { (Head of Stock Broking, FI Group) }\end{array}$ & $\begin{array}{l}\text { Query/ } \\
\text { Suspension/ } \\
\text { Dismissal }\end{array}$ & \\
\hline $\begin{array}{l}\text { No there is no reward, since I have started using it nothing has } \\
\text { changed, no reward except for the fact that it simplifies my work. } \\
\text { (Analyst, FI Group). }\end{array}$ & $\begin{array}{l}\text { No Salary } \\
\text { Rise/ Bonus/ } \\
\text { Promotion }\end{array}$ & $\begin{array}{l}\text { Rewards for } \\
\text { compliance with } \\
\text { controls }\end{array}$ \\
\hline $\begin{array}{l}\text { Despite the force, the monthly dashboard report that comes out of } \\
\text { MAXIM shows that people are really using MAXIM. (Group Head, } \\
\text { IS Group) }\end{array}$ & $\begin{array}{l}\text { Acceptance of } \\
\text { MAXIM }\end{array}$ & \multirow{2}{*}{$\begin{array}{l}\text { Employee } \\
\text { reactions to } \\
\text { control } \\
\text { mechanisms }\end{array}$} \\
\hline $\begin{array}{l}\text { After senior management made it clear it will only accept MAXIM } \\
\text { generated reports, we started to accept that MAXIM is here to stay. } \\
\text { So now we are all using it. (e-Product Administrator, OP Group) }\end{array}$ & $\begin{array}{l}\text { Acceptance of } \\
\text { MAXIM }\end{array}$ & \\
\hline $\begin{array}{l}\text { After the [control] policies put in place by management, everybody } \\
\text { now uses it [MAXIM] and adopts it to achieve higher } \\
\text { organizational performances. (Head Registrars, Finance Group) }\end{array}$ & $\begin{array}{l}\text { Greater user } \\
\text { engagement } \\
\text { with MAXIM }\end{array}$ & \multirow{2}{*}{$\begin{array}{l}\text { Implication of } \\
\text { formal controls on } \\
\text { MAXIM diffusion }\end{array}$} \\
\hline $\begin{array}{l}\text { The measures have worked well. I believe it was an effective way } \\
\text { and also a good way of doing things because it [made] everyone } \\
\text { fully use MAXIM to perform our daily functions to achieve a high } \\
\text { level of performance. (e-Channels administrator, OP Group) }\end{array}$ & $\begin{array}{l}\text { Greater user } \\
\text { engagement } \\
\text { with MAXIM }\end{array}$ & \\
\hline
\end{tabular}

